\title{
Differential response of cancer cells to HDAC inhibitors trichostatin A and depsipeptide
}

\author{
J Chang', DS Varghese', MC Gillam', M Peyton', B Modi', RL Schiltz ${ }^{2}$, L Girard ${ }^{1,3}$ and ED Martinez ${ }^{*, 1,3}$ \\ 'Hamon Center for Therapeutic Oncology Research, UT Southwestern Medical Center, 6000 Harry Hines Boulevard, Dallas, TX 75390-8593, USA; \\ ${ }^{2}$ Laboratory of Receptor Biology and Gene Expression, NCI, NIH, Bethesda, MD 20892, USA; ${ }^{3}$ Department of Pharmacology, UT Southwestern Medical \\ Center, 6000 Harny Hines Boulevard, Dallas, TX 75390-8593, USA
}

BACKGROUND: Over the last decade, several drugs that inhibit class I and/or class II histone deacetylases (HDACs) have been identified, including trichostatin A, the cyclic depsipeptide FR90I228 and the antibiotic apicidin. These compounds have had immediate application in cancer research because of their ability to reactivate aberrantly silenced tumour suppressor genes and/or block tumour cell growth. Although a number of HDAC inhibitors are being evaluated in preclinical cancer models and in clinical trials, little is known about the differences in their specific mechanism of action and about the unique determinants of cancer cell sensitivity to each of these inhibitors.

METHODS: Using a combination of cell viability assays, HDAC enzyme activity measurements, western blots for histone modifications, microarray gene expression analysis and qRT-PCR, we have characterised differences in trichostatin A vs depsipeptide-induced phenotypes in lung cancer, breast cancer and skin cancer cells and in normal cells and have then expanded these studies to other HDAC inhibitors.

RESULTS: Cell viability profiles across panels of lung cancer, breast cancer and melanoma cell lines showed distinct sensitivities to the pan-inhibitor TSA compared with the class I selective inhibitor depsipeptide. In several instances, the cell lines most sensitive to one inhibitor were most resistant to the other inhibitor, demonstrating these drugs act on at least some non-overlapping cellular targets. These differences were not explained by the HDAC selectivity of these inhibitors alone since apicidin, which is a class I selective compound similar to depsipeptide, also showed a unique drug sensitivity profile of its own. TSA had greater specificity for cancer vs normal cells compared with other HDAC inhibitors. In addition, at concentrations that blocked cancer cell viability, TSA effectively inhibited purified recombinant HDACs I, 2 and 5 and moderately inhibited HDAC8, while depsipeptide did not inhibit the activity of purified HDACs in vitro but did in cellular extracts, suggesting a potentially indirect action of this drug. Although both depsipeptide and TSA increased levels of histone acetylation in cancer cells, only depsipeptide decreased global levels of transcriptionally repressive histone methylation marks. Analysis of gene expression profiles of an isogenic cell line pair that showed discrepant sensitivity to depsipeptide, suggested that resistance to this inhibitor may be mediated by increased expression of multidrug resistance genes triggered by exposure to chemotherapy as was confirmed by verapamil studies.

CONCLUSION: Although generally thought to have similar activities, the HDAC modulators trichostatin A and depsipeptide demonstrated distinct phenotypes in the inhibition of cancer cell viability and of HDAC activity, in their selectivity for cancer vs normal cells, and in their effects on histone modifications. These differences in mode of action may bear on the future therapeutic and research application of these inhibitors.

British Journal of Cancer (2012) 1 06, I16-125. doi:10.1038/bjc.2011.532 www.bjcancer.com

Published online 8 December 2011

(C) 2012 Cancer Research UK

Keywords: trichostatin A; depsipeptide; HDAC inhibitors; cancer cell viability; drug sensitivity

Over the last decade, histone deacetylases (HDACs) have been identified as bona fide molecular targets for the treatment of various disorders including cancer. HDACs have pivotal roles in the regulation of gene expression, forming complexes with DNA binding proteins and thereby affecting histone acetylation and chromatin accessibility at promoter regions (Fischle et al, 2001;

*Correspondence: Dr ED Martinez;

E-mail: elisabeth.martinez@utsouthwestern.edu

Received 12 September 2011; revised 28 October 2011; accepted 7

November 201 I; published online 8 December 201 I
Ekwall, 2005; Clapier and Cairns, 2009; Witt et al, 2009). These enzymes also have non-histone substrates, such as transcription factors and structural proteins whose biological activity is partly regulated by acetylation (Di Gennaro et al, 2004; Chen et al, 2005; Zhao et al, 2006; Sadoul et al, 2008). Because deregulation of HDAC function has been found in cancer and other pathologies, inhibitors of HDACs have gained importance as potential therapeutics and as tools for chemical genomics investigations (Shames et al, 2006; Zhong et al, 2007; Marshall et al, 2009).

The HDAC family comprises four classes of deacetylases, grouped by their homology, their expression patterns and subcellular localisation, the cofactors required for their activity, 
and their substrates. Class 1, 2 and 4 HDACs share histones as substrates and utilise zinc for catalytic activity. Inhibitors of these enzymes contain zinc-chelating groups that disrupt enzyme/metal coordination at the active site, thus blocking catalytic activity. Among the well-established HDAC inhibitors, trichostatin A represents the hydroxamic acids which show general inhibition of class 1, 2 and 4 HDACs with nanomolar potency (Schultz et al, 2004; Bieliauskas and Pflum, 2008). Other inhibitors include the short chain fatty acid butyrate, the antibiotic apicidin, and the cyclic peptide FR901228 commonly known as depsipeptide. Depsipeptide has been shown to have selectivity for class 1 HDACs and alters histone modifications in cells at low nanomolar doses, although $\mathrm{IC}_{50}$ (50\% inhibitory concentration) values for HDAC inhibition in vitro are reportedly significantly higher (Schrump et al, 2002; Bieliauskas and Pflum, 2008; Itoh et al, 2008).

These compounds have initially shown promising therapeutic potential in human cancer studies (McLaughlin and La Thangue, 2004; Villar-Garea and Esteller, 2004; Ryan et al, 2005; Lin et al, 2006; Riester et al, 2007; Jones and Steinkuhler, 2008; Prince et al, 2009; Rocca et al, 2009; Takai and Narahara, 2010); yet, the relationship between their HDAC inhibitory activity and their ability to control cancer growth is not clear. In addition, certain sub-populations of patients, benefit little or not at all and side effects range considerably (Schrump et al, 2002; McLaughlin and La Thangue, 2004; Kelly and Marks, 2005; Bolden et al, 2006; Stimson and La Thangue, 2009). At the molecular level, these differences can be partly explained by the fact that tumours express the various HDACs to different extents, and that current inhibitors are generally non-specific, targeting more than one HDAC enzyme and affecting non-histone as well as histone targets. Defining differences in HDAC inhibitor-induced phenotypes across inhibitor structural subgroups and understanding the molecular underpinnings that give rise to these differences is thus an important aspect of the preclinical development of this drug class. Although a number of groups have studied individual HDAC inhibitors and their effects on cell growth, these reports were not comparative across inhibitors and included only a few cell lines (Vigushin et al, 2001; Facchetti et al, 2004; Klisovic et al, 2005; Lee et al, 2006; Mukhopadhyay et al, 2006; Cantor et al, 2007; Miyanaga et al, 2008; Zhang et al, 2008).

Here, we profiled the sensitivity of lung cancer, breast cancer and skin cancer cell line panels in response to pan vs class 1 selective HDAC inhibitors and ranked cells according to their $\mathrm{IC}_{50}$ values. We also characterised the selectivity of these compounds by measuring their effects on normal human bronchial epithelial cells, human mammary epithelial cells and primary melanocytes and analysed their ability to block HDAC activity in purified systems and in cellular extracts at concentrations that impacted cancer cell viability. Furthermore, we identified differences in drug-induced phenotypes with respect to histone modifications and molecular determinants of sensitivity. Altogether, these findings may bear on the future use of these inhibitors and their analogues in personalised medicine applications.

\section{MATERIALS AND METHODS}

\section{Cell culture}

All human cancer cell lines were maintained in RPMI media supplemented with $5 \%$ (lung and breast cancer cells) or $10 \%$ (melanoma cells) fetal bovine serum. Human bronchial epithelial cells immortalised with cdk4 and telomerase were cultured in KSFM media supplemented with EGF and pituitary extract, as described (Ramirez et al, 2004). Human mammary epithelial cells immortalised with telomerase were maintained in complete MEGM media from Cambrex (East Rutherford, NJ, USA). Primary melanocytes were purchased from Cascade Biologics (Portland, OR, USA) and were cultured in Medium 254 with PMA-free human melanocyte growth supplement-2 (also from Cascade Biologics). TSA and apicidin were purchased from Alexis Biochemicals (Enzo Life Sciences, Farmington, NY, USA) and depsipeptide was the kind gift of Dr David Schrump.

\section{Cell viability assays and $\mathrm{IC}_{50}$ calculations}

Cells were plated at 1500-3000 cells per well in 96-well plates and treated the next day with increasing doses of TSA, depsipeptide or apicidin over 4 days and their viability assessed by standard MTS assays using Promega's Cell Titer reagents (Promega, Madison, WI, USA) according to the manufacturer's protocols. Absorbance at 490 and $650 \mathrm{~nm}$ (reference wavelength) was measured by a Spectra Max (Molecular Devices, Sunnyvale, CA, USA) or a FlouroStar Omega (BMG Biosciences, Ortenberg, Germany) plate reader. Data were normalised to the untreated controls $(100 \%$ viability). Each cell line was tested in 1-5 independent assays, each containing 4-8 replicates. $\mathrm{IC}_{50}$ values were calculated using DIVISA, a high-throughput software, developed in-house (manuscript in preparation), for storing and analysing drug sensitivity assays. Dose-response curves were plotted using a non-linear regression model and $\mathrm{IC}_{50} \mathrm{~s}$ were determined from the fitted curves. Average $\mathrm{IC}_{50}$ values derived from 1 to 5 independent assays, each containing 4-8 replicates are shown in Tables 1-3.

\section{HDAC assays}

Cell extracts or purified recombinant HDAC enzymes were used in standard HDAC activity assays using Millipore's HDAC Fluorometric Assay Kit (Millipore, Billerica, MA, USA), according to the manufacturer's protocol. A FluoroStar Omega plate reader (BMG Biosciences) was used for fluorescent detection. Purified recombinant active HDACs 1,5 and 8 were purchased from Millipore/ Upstate. HDAC2 was purified as described below.

\section{Plasmid constructs for recombinant HDAC2 production}

Two SDS - PAGE purified oligonucleotides (Eurofins, London, UK) encoding a carboxy terminal FLAG tag (DYKDDDDK) followed by a stop codon were phosphorylated with T4 polynucleotide kinase (NEB), annealed together and ligated into XhoI and HindIII digested pFastbBac1 (Invitrogen, Carlsbad, CA, USA) to generate pFastBac1-C-FLAG. The sequences of the oligonucleotides are $5^{\prime}-\mathrm{T}$ CGAGGACTACAAGGACGACGATGACAAATGA- $3^{\prime}$ and $5^{\prime}$-AGC TTCATTTGTCATCGTCGTCCTTGTAGTCC-3'. The murine HDAC2 open reading frame was amplified by PCR from the plasmid

Table I IC $\quad C_{50}$ values and sensitivity ranking of lung cancer cells

\begin{tabular}{|c|c|c|c|c|}
\hline NSCLC & TSA $I C_{50}$ & TSA rank & $\begin{array}{c}\text { Depsipeptide } \\
\text { IC }_{50}\end{array}$ & $\begin{array}{c}\text { Depsipeptide } \\
\text { rank }\end{array}$ \\
\hline $\mathrm{HCCl} 5$ & $7.9 \mathrm{nM}$ & 1 & $6.4 \mathrm{nM}$ & 12 \\
\hline $\mathrm{H} 292$ & 22.5 & 2 & 0.7 & 2 \\
\hline H2009 & 38.3 & 3 & 0.9 & 3 \\
\hline A549 & 39.7 & 4 & 2.0 & 7 \\
\hline H358 & 40 & 5 & 1.1 & 4 \\
\hline HI395 & 41 & 6 & 5.3 & | | \\
\hline H820 & 55 & 7 & 4.0 & 10 \\
\hline $\mathrm{H} 2073$ & 63.7 & 8 & 37.1 & 15 \\
\hline HI993 & 93.5 & 9 & 1.2 & 5 \\
\hline HI355 & 107 & 10 & 1.8 & 6 \\
\hline HCC366 & 147 & $1 \mid$ & 3.1 & 8 \\
\hline HI299 & 150 & 12 & 12.1 & 14 \\
\hline HI 437 & 191 & 13 & 0.5 & I \\
\hline H2086 & 275 & 14 & 3.8 & 9 \\
\hline H2085 & 390 & 15 & 6.9 & 13 \\
\hline
\end{tabular}

Abbreviations: $I C_{50}=50 \%$ inhibitory concentration; $N S C L C=$ non-small cell lung cancer cell; TSA = trichostatin A 
Table $\mathbf{2} \quad \mathrm{IC}_{50}$ values and sensitivity ranking of breast cancer and melanoma cells

\begin{tabular}{|c|c|c|c|c|}
\hline BCa line & $\begin{array}{l}\text { TSA } \\
1 C_{50}\end{array}$ & $\begin{array}{l}\text { TSA } \\
\text { rank }\end{array}$ & $\begin{array}{c}\text { Depsipeptide } \\
\qquad \text { IC }_{50}\end{array}$ & $\begin{array}{c}\text { Depsipeptide } \\
\text { rank }\end{array}$ \\
\hline HCCI500 & $29 \mathrm{nM}$ & 1 & $1.5 \mathrm{nM}$ & 4 \\
\hline $\mathrm{HCCl} 806$ & 41 & 2 & 1.8 & 5 \\
\hline $348 \mathrm{~T}^{\mathrm{a}}$ & 81 & 3 & 1.3 & 2 \\
\hline MCF-7 & 90 & 4 & 4.2 & 7 \\
\hline $\mathrm{HCCl} 954$ & 91 & 5 & 1.5 & 3 \\
\hline MCF-IO & 96 & 6 & 2.4 & 6 \\
\hline $1585 \mathrm{~T}^{\mathrm{a}}$ & 124 & 7 & 1.3 & 1 \\
\hline Melanoma & $\begin{array}{l}\text { TSA } \\
I_{50}\end{array}$ & $\begin{array}{l}\text { TSA } \\
\text { rank }\end{array}$ & $\begin{array}{l}\text { Depsipeptide } \\
\text { IC }_{50}\end{array}$ & $\begin{array}{c}\text { Depsipeptide } \\
\text { rank }\end{array}$ \\
\hline LOXIMVI & $57 \mathrm{nM}$ & I & $1.2 \mathrm{nM}$ & 5 \\
\hline SKMEL5 & 66 & 2 & 1.5 & 6 \\
\hline MI4 & 98 & 3 & 2.4 & 8 \\
\hline UACC257 & 222 & 4 & 1.6 & 7 \\
\hline UACC62 & 238 & 5 & 0.9 & 4 \\
\hline MALME3M & 240 & 6 & 0.7 & 2 \\
\hline SKMEL2 & 336 & 7 & 0.4 & 1 \\
\hline SKMEL28 & 400 & 8 & 0.8 & 3 \\
\hline $\begin{array}{l}\text { Uveal } \\
\text { Melanoma }\end{array}$ & $\begin{array}{l}\text { TSA } \\
1 C_{50}\end{array}$ & \multicolumn{2}{|c|}{$\begin{array}{c}\text { Depsipeptide } \\
\text { IC }_{50}\end{array}$} & $\begin{array}{l}\text { Apicidin } \\
\text { IC }_{50}\end{array}$ \\
\hline MEL270 & $68 \mathrm{nM}$ & \multicolumn{2}{|r|}{$1.8 \mathrm{nM}$} & $0.65 \mu \mathrm{M}$ \\
\hline OCMI & 188 & \multicolumn{2}{|r|}{5.5} & 0.7 \\
\hline OCM3 & 220 & \multicolumn{2}{|r|}{1.5} & 4 \\
\hline OMM2.3 & 81 & \multicolumn{2}{|r|}{2.7} & 0.4 \\
\hline
\end{tabular}

Abbreviations: $I C_{50}=50 \%$ inhibitory concentration; TSA = trichostatin A. ${ }^{a} \mid m m o r t a l i s e d$ normal human mammary epithelial cells.

Table $3 \quad I C_{50}$ values for human bronchial epithelial cells, patient matched normal/lung cancer lines and melanocytes

\begin{tabular}{|c|c|c|c|}
\hline Cell line & \multicolumn{2}{|c|}{ TSA IC $50, n M$} & Depsipeptide $I C_{50}, \mathrm{nM}$ \\
\hline HBEC3KT & \multicolumn{2}{|c|}{318} & I \\
\hline HBECI5KT & \multicolumn{2}{|c|}{295} & 2.5 \\
\hline HBECI6KT & \multicolumn{2}{|c|}{260} & 4.9 \\
\hline Cell line & TSA IC ${ }_{50}, \mathrm{nM}$ & $\begin{array}{l}\text { Depsipeptide } \\
\text { IC }_{50}, \mathrm{nM}\end{array}$ & Apicidin $\mathrm{IC}_{50}, \mu \mathrm{M}$ \\
\hline HBEC3OKT & 285 & 0.9 & 0.09 \\
\hline HCC4017 & 73 & 6.5 & 0.12 \\
\hline HBEC34KT & 346 & 1.3 & 0.79 \\
\hline HCC40I8 & 23 & 4.2 & 0.03 \\
\hline Melanocytes & 284 & 0.9 & 0.2 \\
\hline
\end{tabular}

Abbreviations: $I_{50}=50 \%$ inhibitory concentration; $T S A=$ trichostatin $A$.

pME18S-HDAC2 (a generous gift form Robert Eisenman). The sequences of the PCR amplification oligonucleotides (Eurofins) are $5^{\prime}$-GATCGGATCCATGGCGTACAGTCAAGGAGGCGGCAAG- $3^{\prime}$ and $5^{\prime}$-GGATCTCGAGAGGGTTGCTGAGTTGTTCTGACTTG-3'. The resulting PCR product was digested with BamHI (NEB) and XhoI (NEB) and ligated into BamHI and XhoI digested pFastBac1-CFLAG. The resulting plasmid is pFastBac1-mHDAC2-C-FLAG.

\section{Production of recombinant baculovirus and FLAG affinity purification of HDAC2}

pFastBac1-mHDAC2-C-FLAG was used to produce recombinant baculovirus using the Bac-to-Bac Baculovirus Expression System (Invitrogen) according to the manufacturer's protocol. Recombinant murine HDAC2 baculovirus at an MOI of 10 was used to infect five T162 monolayer flasks seeded with $4 \times 10^{7}$ Sf9 cells per flask in Sf900-II-SFM (Invitrogen) serum-free media. Infected cells were harvested $48 \mathrm{~h}$ post infection and processed for FLAG affinity purification as previously described in Supplementary Data (Qiu et al, 2006).

\section{Western blot analysis}

Exponentially growing cells were treated with the appropriate compounds and harvested 4 or $24 \mathrm{~h}$ later in a standard nuclear lysis buffer and whole cell lysates were quantified. Equal amounts of total protein were loaded onto $4-12 \%$ Bis-Tris SDS gels and subjected to electrophoresis. After transferring onto nitrocellulose membranes, blots were probed for acetylated tubulin (Sigma, St Louis, MO, USA; T6793), acetylated histone 3 (Millipore/Upstate \#06-599), acetylated histone 4 (Millipore/Upstate \#07-329) or trimethylated histone 3 at lysine 9 (Millipore/Upstate \#07-523). Actin (Santa Cruz, Santa Cruz, CA, USA; \#1616) and HDAC1 (Affinity Bioreagents, Rockford, IL, USA; \#PA1-860) were probed as loading controls. Quantification of bands in films was performed using two independent methods, which yielded similar results, Image J (NIH public software) and Quantity one (Bio-Rad, Hercules, CA, USA). The average of the two methods \pm s.e.m. is shown as specified in figure legends. For the MDR western analysis, a primary antibody against P-glycoprotein from Calbiochem (Darmstadt, Germany) was used according to the manufacturer's recommendations and HSP90 (Santa Cruz) was used as a loading control.

\section{Microarray gene expression profiles}

Exponentially growing $\mathrm{H} 1993$ and $\mathrm{H} 2073$ cells were pelleted and RNA was extracted using the RNeasy kit (Qiagen, Valencia, CA, USA) according to the manufacturer's protocol. RNA quality was evaluated with the Experion gel system (Bio-Rad). Labelled RNA was hybridised to Affymetrix (Cleveland, OH, USA) HG-U133Plus2 microarray chips according to the manufacturer's protocol and scanned using the Affymetrix GeneChip Scanner 2500. After pre-processing using the mas5 algorithm (Bioconductor, Affymetrix), gene expression changes were analysed using the Matrix 1.4 software package developed in-house. Selected genes showing differential expression levels greater than four-fold were further investigated by $\mathrm{qRT}-\mathrm{PCR}$ and functional relationships were analysed with the Ingenuity Pathway gene annotation software (Ingenuity Systems, Redwood City, CA, USA).

\section{Quantitative real-time PCR}

Exponentially growing cells were processed for RNA extraction using RNeasy (Qiagen). The extracted RNA was quantified, DNAse treated and reverse transcribed. The resulting cDNA was amplified in SybrGreen real-time quantitative PCR assays using validated primers specific for the genes of interest (sequences are given in Supplementary Table 2). Reactions were performed on an ABI Prism 7900HT (Life Technologies, Carlsbad, CA, USA), with an initial $2 \mathrm{~min}$ pre-incubation at $50^{\circ} \mathrm{C}$, followed by $10 \mathrm{~min}$ at $95^{\circ} \mathrm{C}$ and then 40 cycles of $95^{\circ} \mathrm{C}$ for $15 \mathrm{~s}$ and $60^{\circ} \mathrm{C}$ for $1 \mathrm{~min}$. Cyclophilin and $18 \mathrm{~S}$ ribosomal RNA were used as references. Data were analysed following the ddCt method using a calibrator sample. Reactions were run in triplicate and error bars represent experimental error.

\section{RESULTS}

\section{Cancer cell sensitivity to TSA and depsipeptide show distinct profiles}

Our goals were to profile the sensitivity of cancer cells to the HDAC inhibitors trichostatin A and depsipeptide, to compare their 
A
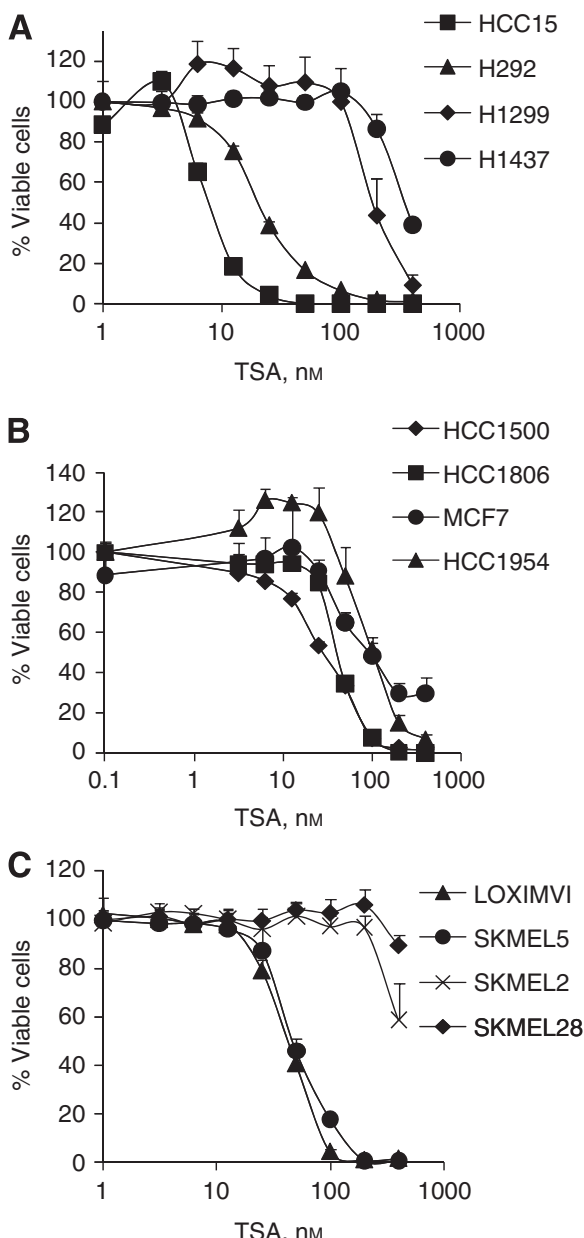
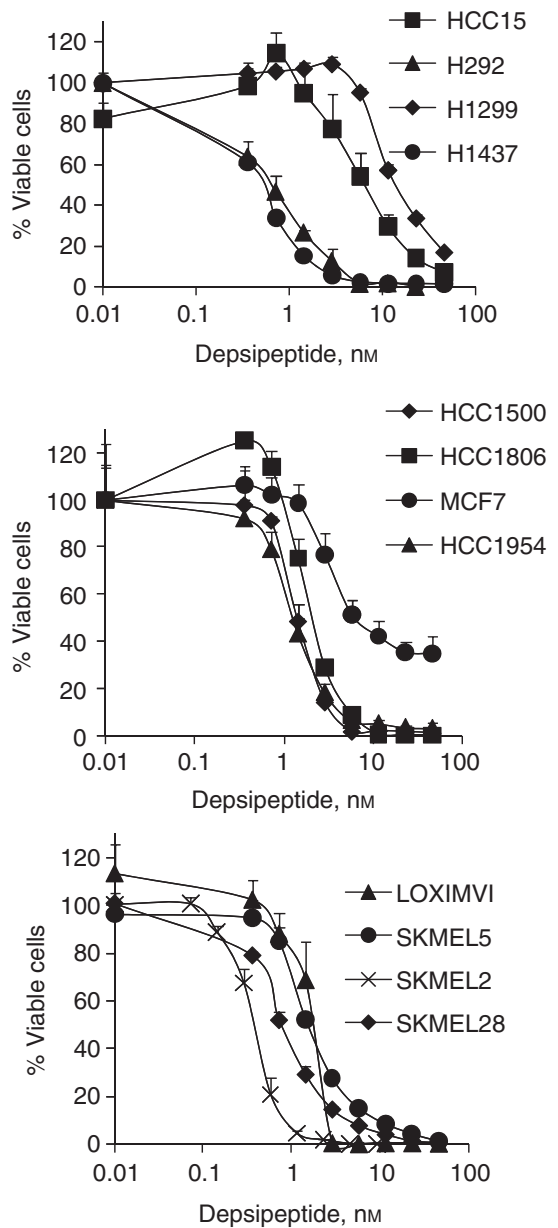

Figure I Human cancer cell lines show distinct sensitivities to HDAC inhibitors TSA and depsipeptide. The viability of human non-small lung cancer lines $(\mathbf{A})$, breast cancer cells $(\mathbf{B})$ and melanoma cells $(\mathbf{C})$ was assessed after 4 days exposure to increasing concentrations of TSA (left panels) or depsipeptide (right panels) using standard MTS assays. See Supplementary Figure I for further cell line comparisons.

relative potency and specificity across panels of lung cancer, breast cancer and melanoma cell lines, and to define phenotypes unique to each inhibitor. To assess whether human non-small cell lung cancer cells responded differentially to the pan-inhibitor TSA $v s$ the class 1 selective inhibitor depsipeptide, we performed MTS cell viability assays for each drug on a panel of lines (Figure 1A; Supplementary Figure 1). $\mathrm{IC}_{50}$ measurements revealed that although some cell lines such as H292 and H1299 shared similar relative sensitivity to these two inhibitors (H292 is sensitive to both TSA and depsipeptide and H1299 is on the resistant end of both drug profiles, as shown in Figure 1A and Table 1), others showed opposite drug phenotypes being preferentially responsive to TSA and relatively resistant to depsipeptide or vice versa. HCC15, for example, demonstrated strong sensitivity to TSA, yet was among the most resistant lines to depsipeptide. Analogously, H1437 was strongly resistant to TSA treatment but was sensitive to depsipeptide. Similar differences across cell lines were also observed using other measures of cell viability (Supplementary Figures $2 \mathrm{~A}$ and $\mathrm{B}$ ).

Next, we wanted to evaluate if the distinct relative sensitivities to TSA $v s$ depsipeptide of these lung cancer cell lines would generally hold for other pan $v s$ class 1 selective inhibitors. Indeed, HCC15 cells were more sensitive to the pan-inhibitor Scriptaid compared with H1437 cells (Supplementary Figure 2C), following a TSA-like pattern. Similarly, MS-275, a class 1 selective HDAC inhibitor, exhibited a depsipeptide-like profile being more potent against H1437 cells than HCC15 cells (Supplementary Figure 2D). Thus, also in this case the relative sensitivity of $\mathrm{H} 1437$ and HCC15 cells to HDAC inhibitors of differential specificity followed opposite patterns.

To begin to understand cellular mechanisms that may contribute to the relative sensitivity of lung cancer cells to TSA or depsipeptide, we performed $\mathrm{qRT}-\mathrm{PCR}$ analysis measuring HDAC levels in a subset of lines. Interestingly, we found that HDAC2 was markedly upregulated in H1299 cells, which showed general resistance to both TSA and depsipeptide, compared with H292 cells, which are sensitive to both inhibitors (Supplementary Figure 3A). Other class 1 HDACs also showed a slight trend of upregulation in H1299. In contrast, when comparing levels of HDACs in cells with distinct sensitivities to TSA $v s$ depsipeptide, such as H1437 to HCC15, we saw no clear differences in class 1 HDAC levels (Supplementary Figure 3B). Instead, we did observe an upregulation of class 2 HDACs in HCC15 vs H1437 (Supplementary Figure 3C), suggesting the relative resistance of HCC15 to depsipeptide may in part be related to the uninhibited and redundant action of the upregulated class 2 HDACs.

Differences in relative sensitivity to HDAC inhibitors were also observed in human breast cancer lines. As can be seen in Figure 1B, MCF7 cells responded differently to TSA than to depsipeptide: while they showed intermediate sensitivity to TSA treatment, MCF7 cells were relatively resistant to depsipeptide and exhibited a $30-40 \%$ surviving population. In contrast, HCC1954 cells were the most resistant tested breast cancer line to TSA, but the most sensitive line to depsipeptide (Figure 1B; Table 2). 

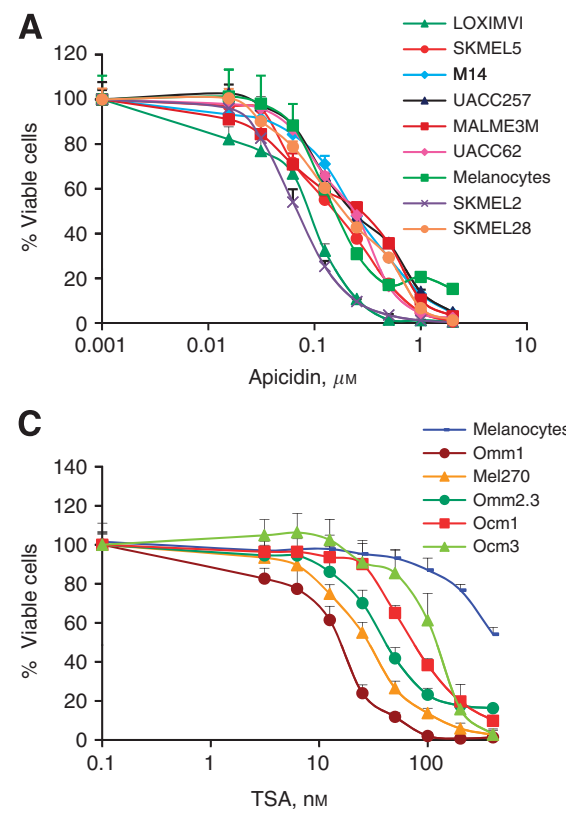
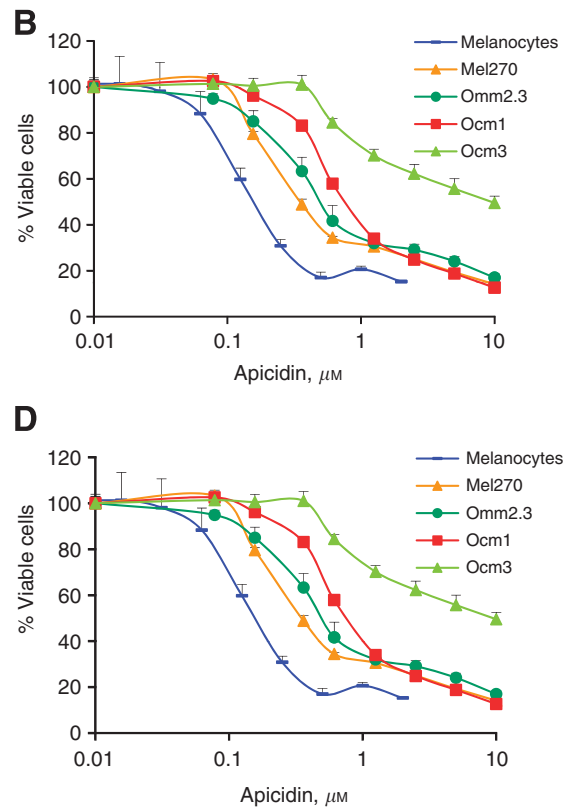

Figure 2 Unique cell viability profiles of apicidin, TSA and depsipeptide across cutaneous and uveal melanomas. Cutaneous (A) and uveal melanoma cells (B) were treated with increasing doses of apicidin and cell viability was measured by MTS assays after 4 days. The sensitivity of uveal melanoma cells to TSA (C) and depsipeptide (D) was also measured and compared with the response of primary melanocytes.

Differential patterns were also seen in melanoma cells, which showed distinct sensitivities to the two inhibitors as well (Figure 1C; Table 2). Strikingly, SK-MEL2 and SK-MEL28 were the most sensitive cutaneous melanomas to depsipeptide inhibition but were unaffected by TSA treatment except at the highest dose. SK-MEL5 and LOXIMVI, on the other hand, showed low sensitivity to depsipeptide but high sensitivity to TSA.

To further evaluate the behaviour of cells in response to HDAC inhibitors, we measured the effects of a third, structurally distinct compound, apicidin, on the melanoma cell panel and expanded the study to include uveal melanomas (Ren et al, 2004). Apicidin, which like depsipeptide has some selectivity for class 1 HDACs (Bieliauskas and Pflum, 2008), did not generally mimic the drug sensitivity profiles of either depsipeptide or TSA, showing a narrower range of activity with a smaller distribution of $\mathrm{IC}_{50}$ values across the non-uveal melanoma cell line panel (compare Figure 2A with Figure 1C). Nevertheless, SK-MEL2 was on the sensitive side of the apicidin spectrum in a depsipeptide-like manner but LOXIMVI was also sensitive to apicidin, following the TSA pattern. In uveal melanomas, TSA and apicidin clearly showed similar sensitivity profiles with $\mathrm{IC}_{50}$ values for $\mathrm{Mel} 270<\mathrm{Omm} 2.3$ $<\mathrm{Ocm} 1<\mathrm{Ocm} 3$ for both compounds (Figure $2 \mathrm{~B}$ and $\mathrm{C}$ ). In contrast to Ocm3's relative resistance to TSA and apicidin, this cell line was sensitive to depsipeptide (Figure 2D), demonstrating that cells can respond differentially even to structurally distinct class 1 selective HDAC inhibitors. Taken together, these data suggest that indeed, each HDAC inhibitor structural class has a unique drug sensitivity profile indicative of differences in the mode of action of these compounds and in their interaction with cellular targets. As discussed below, the specificity of HDAC inhibitors for cancer $v s$ normal cells also exhibited unique patterns across compounds and tissue types.

\section{TSA but not depsipeptide or apicidin shows general specificity for cancer $v s$ normal cells}

To determine if normal cells also showed a differential response to HDAC inhibitors and to measure the selectivity of these drugs for cancer cells $v s$ normal cells, we performed cell viability assays on a series of immortalised human bronchial epithelial cells (HBECs) that are non-tumourigenic (Ramirez et al, 2004; Sato et al, 2006). TSA was cancer selective, showing higher $\mathrm{IC}_{50}$ values for HBECs than for most lung cancer cells (Figure 3A; Table 3). In contrast, depsipeptide lacked this specificity and blocked the viability of HBECs with similar or greater potency than of lung cancer cells (Figure $3 \mathrm{~A}$ bottom panel and compare Table 1 values with Table 3 values). The greater ability of TSA $v s$ depsipeptide to preferentially target human cancer $v s$ mammary epithelial cells was also seen in breast cells (Table 2; Supplementary Figure 1B). On the other hand, primary melanocytes showed resistance to both TSA and depsipeptide compared with cutaneous melanomas, but melanocytes were as sensitive to apicidin as most melanoma cells. Compared with uveal melanomas, primary melanocytes showed greater resistance to TSA than even Ocm3 cells - which have a high $\mathrm{IC}_{50}$ for this drug - moderate resistance to depsipeptide and full sensitivity to apicidin (Tables 2 and 3). Thus, TSA is the most selective of these three HDAC inhibitors while apicidin generally lacks selectivity for cancer $v s$ normal cells.

A comparison of TSA's effect on matched pairs of lung cancer and HBEC lines derived from the same patient further demonstrated its preferential selectivity for cancer cells. In two independent pairs, TSA showed greater potency against the lung cancer line than against the corresponding patient-matched HBEC line, with a difference in $\mathrm{IC}_{50}$ values within a pair ranging from 5 - to $\gg 20$-fold (Figure 3B; Table 3). Depsipeptide showed a slight selectivity of about three- to five-fold and apicidin was equally potent against one matched lung cancer/HBEC pair showing no selectivity, but was $\sim 25$-fold specific for cancer in the second pair of lines (Figure 4C). These results confirm the hydroxamic acid TSA as the most cancer-specific HDAC inhibitor compared with the other compounds tested.

\section{TSA inhibits HDAC activity at concentrations that block cancer cell viability and depsipeptide lowers global histone methylation levels}

To explore whether the function of HDACs was modulated by inhibitors at concentrations that block cancer cell viability, we performed enzyme activity assays in purified systems and in cell extracts. TSA's effective killing dose of $400 \mathrm{~nm}$ fully inhibited 
A
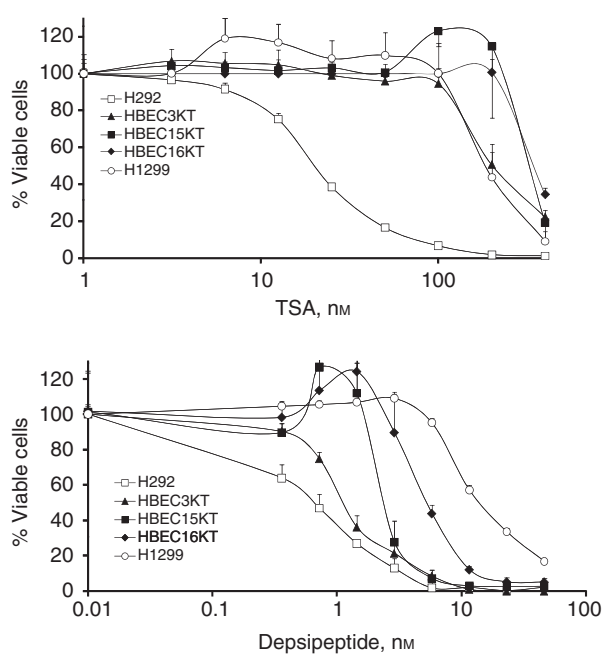

B
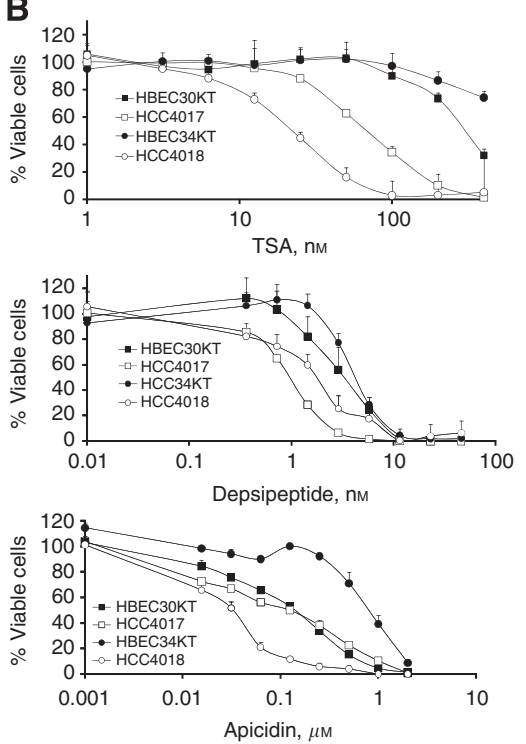

Figure 3 TSA shows greater specificity for cancer than depsipeptide and apicidin. (A) Immortalised human bronchial epithelial cells were treated with TSA (top) or depsipeptide (bottom) in a dose-response series and cell viability assessed 4 days later. H292, which is on the sensitive side of the TSA response and of the depsipeptide response is shown for comparison. HI299, a line on the resistant end of both the TSA and depsipeptide profiles is also shown. HBECs are resistant to TSA but show intermediate sensitivity to depsipeptide. (B) Two patient-matched pairs of human bronchial epithelial cells/ human non-small lung cancer cells were treated with increasing concentrations of the three HDAC inhibitors. TSA showed the largest and most general selectivity for cancer vs normal cells. HCC40I7 was derived from the same patient as HBEC30KT, and HCC40I8 was derived from the same patient as HBEC34KT.
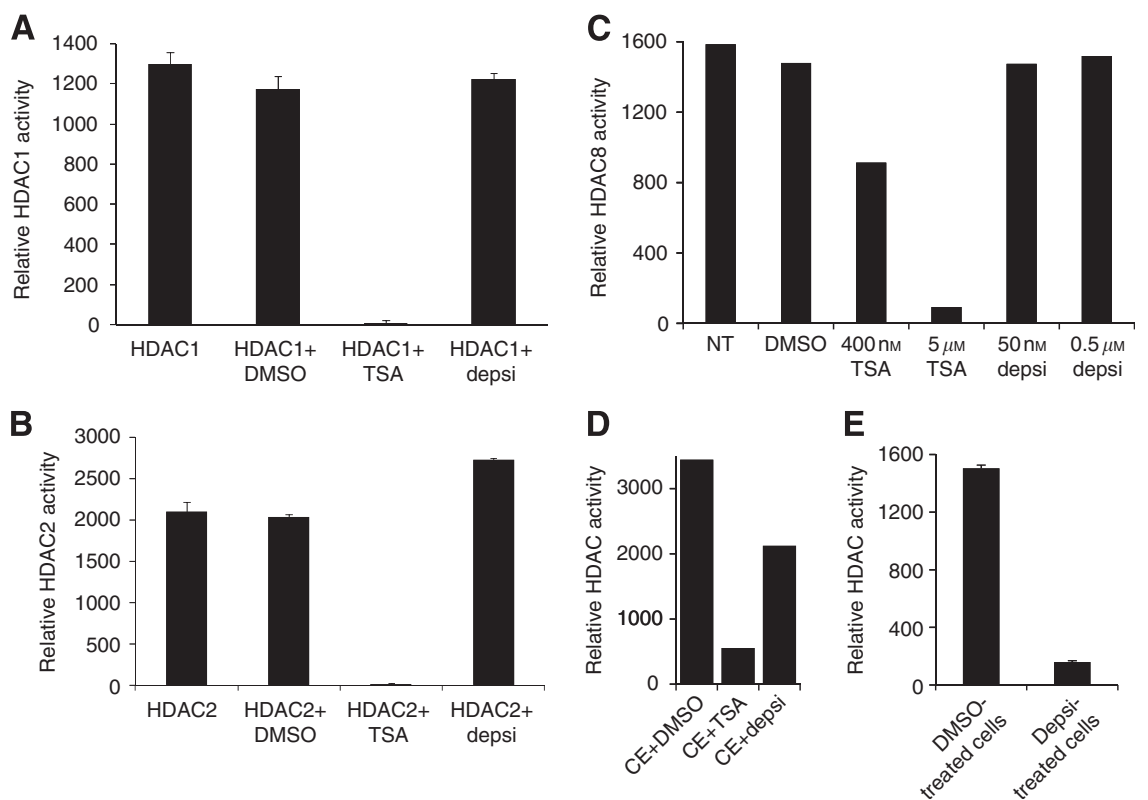

Figure 4 TSA inhibits HDAC activity in vitro at doses that block cancer cell growth. (A) The activity of purified HDACI was measured in the presence of $400 \mathrm{nM}$ TSA or $50 \mathrm{nM}$ depsipeptide, as indicated. (B) HDAC2 activity was quantified in vitro after treatment with vehicle, $400 \mathrm{nM}$ TSA or $0.5 \mu \mathrm{M}$ depsipeptide. (C) HDAC8 activity was measured in the presence of the indicated drug treatments. (D) Cell extracts treated in vitro with I50 nM TSA or $20 \mathrm{nM}$ depsipeptide showed decreased total HDAC activity. (E) Lysates from cells treated with $25 \mathrm{nM}$ depsipeptide show a strongly reduced total HDAC activity. C127 cells which have good levels of HDACs were used for $(\mathbf{D})$ and $(\mathbf{E})$. Drug-treated Baf3 lysates gave equivalent results.

HDAC1 activity, while depsipeptide's effective killing dose of $50 \mathrm{~nm}$ produced no inhibition (Figure 4A). Similarly, HDAC2 enzymatic function was fully inhibited by $400 \mathrm{~nm}$ TSA, but depsipeptide did not decrease HDAC2 activity, which remained unaffected even in the presence of 10-fold higher concentrations of depsipeptide (Figure 4B). HDAC5 activity was similarly sensitive to TSA inhibition but not to depsipeptide (data not shown). As shown in Figure 4C, the most resistant enzyme was HDAC8, which was only partly inhibited by $400 \mathrm{nM}$ TSA, a concentration that fully inhibits cancer cell viability. However, $5 \mu \mathrm{M}$ TSA fully eliminated its activity. Depsipeptide at either $50 \mathrm{nM}$ or $0.5 \mu \mathrm{m}$ had no effect on HDAC8. Interestingly, total HDAC activity in cell extracts treated with inhibitors in vitro was blocked by TSA and was partly inhibited by depsipeptide (Figure 4D). Furthermore, lysates made from depsipeptide treated cells showed a strong inhibition of total HDAC activity compared with lysates made from DMSO-treated 
A

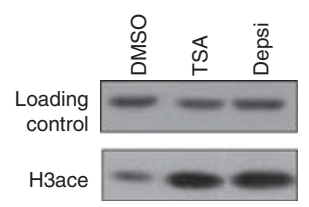

C

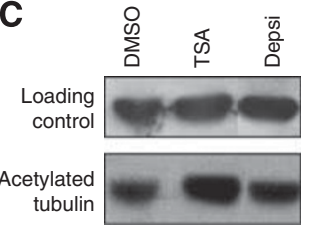

B
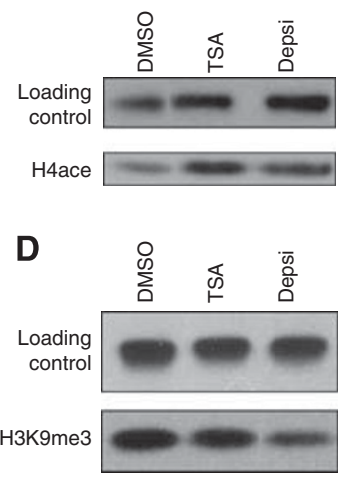

E
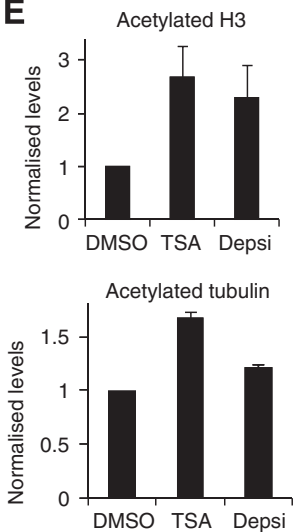
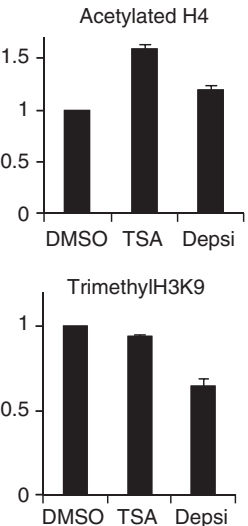

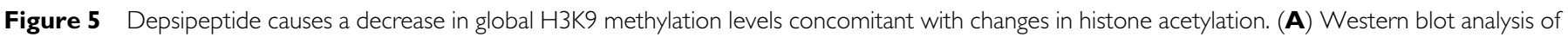
non-small cell lung cancer H358 cells treated for $24 \mathrm{~h}$ with 200 nM TSA, 25 nM depsipeptide or vehicle showed increased levels of histone 3 acetylation in response to both inhibitors. (B) Cells treated as in $(\mathbf{A})$ but for $4 \mathrm{~h}$ were assessed for global levels of histone 4 acetylation. (C) Acetylated tubulin levels in $\mathrm{H358}$ cells treated for $24 \mathrm{~h}$ as in $(\mathbf{A})$ increase in response to TSA. (D) H358 cells treated with 25 nM depsipeptide but not those treated with 200 nM TSA showed lowered levels of histone 3 lysine 9 trimethylation. Irrelevant bands were removed from gels for clarity of presentation. (E) Quantification of western analysis. The average quantification using two independent methods is shown, normalised to DMSO values. For acetylated tubulin two loading controls were run (actin, shown in $\mathbf{C}$ and $\mathrm{HDACl}$ ) giving similar results. The average of the two controls is shown. Error bars represent s.e.m.

cells (Figure 4E), suggesting that depsipeptide requires activation by cellular enzymes and that it may exert at least some of its biological effects through mechanisms that affect HDAC activity indirectly in intact cells.

Consistent with this inhibition of HDAC activity, we found that both TSA and depsipeptide had the ability to alter global histone modifications in lung cancer cells treated with these compounds. Western blot analysis of H358 cells showed that TSA as well as depsipeptide globally increased levels of histone 3 and histone 4 acetylation (Figures 5A, B and E). TSA also altered the amounts of acetylated tubulin, a known non-histone substrate of HDAC6 (Figures 5C and E). Given the ability of TSA and depsipeptide to increase histone acetylation and thus shift chromatin towards a state of higher transcriptional activity, we evaluated whether these acetylation effects would be accompanied by HDAC-independent changes in histone methylation at repressive marks. Remarkably, we found that depsipeptide treatment reproducibly decreased global levels of histone 3 trimethylated at lysine 9, while TSA had no effect on this repressive modification (Figures 5D and E). Thus, it appears that depsipeptide's mode of action involves mechanisms that both increase transcriptionally permissive marks on histones and that directly or indirectly decrease transcriptionally repressive marks, unlike TSA.

\section{Determinants of HDAC inhibitor sensitivity}

We next studied the drug responsiveness of matched pairs of cancer cell lines to begin to understand the determinants of cellular sensitivity to specific HDAC inhibitors. H2073 and H1993 are derived from the primary lung tumour and a lymph node metastatic lesion, respectively, of the same patient. H1993 was established before and H2073 after the patient had undergone chemotherapy (Phelps et al, 1996). Strikingly, although H2073 and H1993 show very similar sensitivity to TSA, H1993 is highly responsive to depsipeptide while $\mathrm{H} 2073$ is $>25$-fold more resistant to this drug (Figure 6A). A second pair of primary/lymph node cell lines showed almost identical sensitivity to depsipeptide (Figure 6A, H2085/H2086), demonstrating the differential sensitivity to depsipeptide is particular to the $\mathrm{H} 2073 / \mathrm{H} 1993$ pair and not to primary vs metastatic cells. We reasoned, therefore, that studying what distinguishes H2073 from H1993 could help define the sources of phenotypic differences in the response to HDAC inhibitors and give insights into resistance to targeted therapy, which may develop after exposure to chemotherapy, as in the case of $\mathrm{H} 2073$.

Microarray analysis comparing gene expression profiles of H2073 vs H1993 uncovered groups of genes with distinguishable levels of expression across the cell line pair (Supplementary Table 1). H1993 showed higher expression than H2073 of certain histone variants and chromatin factors, targets that may specifically contribute to sensitivity to depsipeptide and may be downregulated by chemotherapy (Supplementary Table 1; Supplementary Figure 4). For example, H1993 expresses about five-fold higher levels of JMJD2B, a Jumonji enzyme that demethylates trimethylated $\mathrm{H} 3$ at $\mathrm{K} 9$, than $\mathrm{H} 2073$. Yet, there are no changes in the expression of the functionally antagonistic histone methylases across this cell line pair (not shown). Given that depsipeptide but not TSA action involves decreases in $\mathrm{H} 3 \mathrm{~K} 9$ trimethylation levels, it can be speculated that the higher levels of JMJD2B in H1993 would facilitate depsipeptide action. Among the genes differentially expressed in H2073 compared with H1993, genes involved in glutathione metabolism were strongly upregulated as validated by qRT-PCR analysis (Supplementary Table 1; Supplementary Figure 4), suggesting that depsipeptide action but not TSA action is thwarted by glutathione detoxification pathways in H2073. This is interesting since although depsipeptide is thought to require reduction for its cellular activity (mediated by glutathione and other cellular reducers), the reduced drug is significantly less stable and chemotherapy-related ROS production can interfere with depsipeptide reduction (Furumai et al, 2002; Crabb et al, 2008; Itoh et al, 2008).

A second group of highly upregulated genes in H2073 were members of the multidrug resistance family, namely ABCB1 (MDR1), ABCC2 (MRP2) and ABCC6 (MRP6). Depsipeptide, but not TSA, has been reported to be a substrate of ABCB1/ MDR1 (Peart et al, 2003). Thus, it is likely that depsipeptide effluxes from $\mathrm{H} 2073$ cells and that this contributes to their resistance. In agreement with this idea, we found high protein levels of $\mathrm{ABCB} 1 / \mathrm{MDR} 1$ in $\mathrm{H} 2073$ cells compared with undetectable levels in H1993 cells (Figure 6C) and treatment of H2073 cells with the MDR1 inhibitor verapamil partly re-sensitised H2073 cells to depsipeptide while not affecting H1993 cells (Figure 6D). Taken together, these results suggest that chemotherapy-resistant residual disease will likely also be resistant to depsipeptide primarily due to the upregulation of MDR genes but may still respond to TSA. 
A

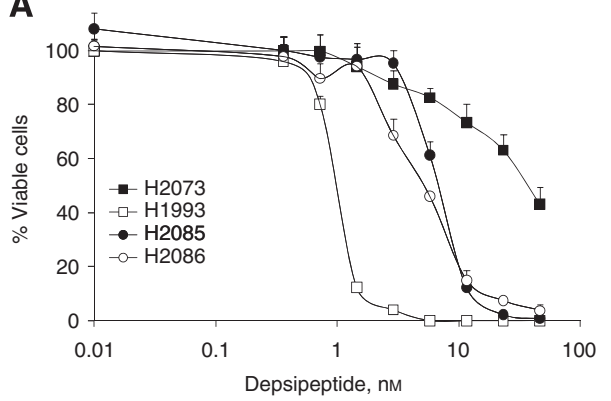

B

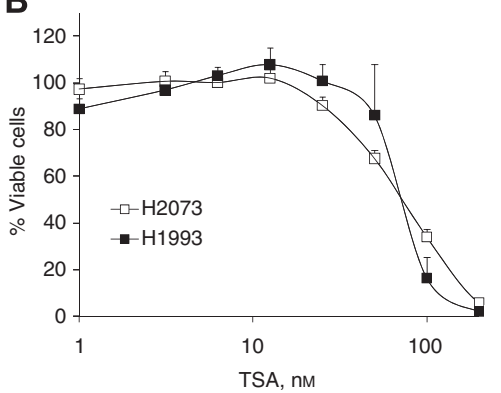

D

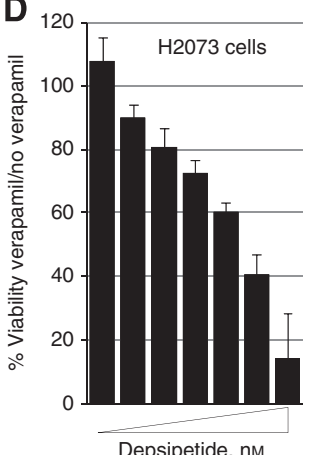

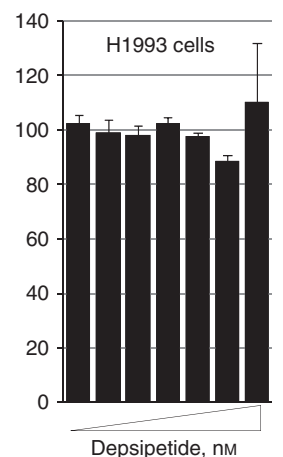

Figure 6 A primary/lymph node cell line pair shows distinct sensitivity to depsipeptide due to chemo-induced upregulation of MDR genes. (A) The sensitivity of two matched primary/lymph node cell line pairs in response to increasing amounts of depsipeptide was measured by MTS assays after 4 days of drug exposure. The H2085/H2086 pair showed almost identical dose-response curves, while the HI993 was remarkably more sensitivity to inhibition by depsipeptide than H2073. (B) The H2073/HI993 pair showed no differential sensitivity to TSA. (C) Western blot analysis confirmed upregulation of the ABCBI/MDRI protein in the chemo-resistant H2073 line. (D) Inhibition of ABCBI/MDRI by verapamil partly restores sensitivity to depsipeptide in H2073 cells without affecting HI993.

\section{DISCUSSION}

By studying the drug sensitivity profiles of several HDAC inhibiors across panels of lung cancer, breast cancer and melanoma cells we have identified unique patterns of drug response specific for each inhibitor. Interestingly, the pan-inhibitor TSA showed greater specificity for cancer $v s$ normal cells than the class 1 selective inhibitors depsipeptide and apicidin. TSA inhibited HDAC activity in purified systems in vitro, while depsipeptide's inhibition of HDACs at doses that blocked cancer cell viability required components of cell extracts. Consistent with this, we found that although both drugs increased global histone acetylation levels, only depsipeptide caused a concomitant decrease in global levels of the repressive histone 3 lysine 9 trimethylation mark, indicating that depsipeptide may indirectly affect other factors in addition to its HDAC inhibitory activity. Microarray gene expression analysis of an isogenic cell line pair, which showed identical sensitivity to TSA but discrepant sensitivity to depsipeptide, revealed that resistance to the cyclic peptide inhibitor may be mediated at least in part by chemotherapy-induced increases in multidrug resistance gene expression. Thus, in spite of targeting the same enzyme family, the various HDAC inhibitors studied here each demonstrated unique phenotypes that may impact the current clinical development of this drug class.

The divergent patterns of drug sensitivity of human cancer cells across HDAC inhibitors we observed allowed us to conclude that each inhibitor, including those that have selectivity for class 1 HDACs, must have activities beyond just HDAC inhibition, which contribute to overall drug effects such as cytotoxicity. In the case of depsipeptide, one such activity may be its ability to lower global levels of histone methylation as we observed at concentrations that blocked the viability of cancer cells. Consistent with this, Wu et al (2008) have reported decreased H3K9 methylation at promoters of genes upregulated by depsipeptide. The global changes in $\mathrm{H} 3 \mathrm{~K} 9$ methylation we see in response to depsipeptide but not TSA suggest that depsipeptide may potentially affect the activity or level of histone methylases or demethylases directly, as was shown in H719 cells for G9a and SUV39H1 (Wu et al, 2008). We did not observe any significant differences, however, in the basal levels of these methylases across cells with a range of depsipeptide sensitivities (data not shown).

In our analysis of drug sensitivity profiles, we found that cancer cell responsiveness to the HDAC inhibitors tested in this study was independent of the histological characteristics and the stage of the tumour from which the cell lines were derived. Likewise, we found no general correlation between drug sensitivity and the available mutational status of cells. Interestingly, however, one of the cell lines that showed resistance to TSA but was sensitive to depsipeptide, H1437, has been recently found to harbour a mutation in HDAC9 (Forbes et al, 2010), a class 2 HDAC. Whether this may be a feature that contributes to TSA resistance generally, remains open to investigation. It is tempting to speculate that molecular determinant of responsiveness may be uncovered by a more thorough analysis of the molecular features of the cell line panels used here, analogous to the discovery of the correlation between EGFR mutations and hypersensitivity to tyrosine kinase inhibitors (Lynch et al, 2004).

Surprisingly, we did see a large shift in responsiveness to depsipeptide, but not other HDAC inhibitors, in two cell lines, one derived from a lymph node lesion before chemotherapy treatment, the other derived from the primary tumour after exposure to etoposide and cisplatin. Comparison of this isogenic pair by microarray gene expression profiling indicated that higher levels of enzymes in the glutathione pathway corresponded to resistance to depsipeptide seen in the line derived after chemotherapy. Xiao et al (2003) reported the presence of various glutathione-depsipeptide conjugates in serum, and proposed that these may represent metabolites with altered activity. In addition, 
depsipeptide's disulphide bond is subject to reduction and this appears to require cytosolic activities and to increase the potency of depsipeptide and its analogues (Xiao et al, 2003; Crabb et al, 2008), yet decreasing the active drug's stability. The glutathione pathway enzymes upregulated in H2073 may potentially affect this reduction and/or increase depsipeptide conjugation to reduced glutathione (through the action of GSTP1, GSTA4 and GSTM3, for example), keeping the cyclic peptide in a less stable form. The connection between drug potency and the status of the disulphide bond within depsipeptide may also help explain the lack of inhibition of HDACs in purified systems at concentrations that had clear biological effects in cells and lysates. Whether sensitivity to depsipeptide may be compromised by prior exposure to chemotherapy in clinical settings remains an open possibility, supported by our data, which must be taken into consideration for future trials.

Despite the greater general potency of depsipeptide compared with TSA or apicidin, the specificity profile of this drug was inferior to that of TSA. Thus, although less selective as an HDAC inhibitor, TSA was the most specific anticancer agent, preferentially targeting cancer $v s$ normal cells. A TSA analogue, SAHA/ vorinostat, has been approved for clinical use by the FDA against cutaneous T-cell lymphoma (Duvic and $\mathrm{Vu}, 2007$ ) with a toxicology and side effect profile that meets standards. To date, therapeutic use of depsipeptide or apicidin analogues or other HDAC inhibitors has not been approved, although clinical trials are ongoing (Sandor et al, 2002; Ryan et al, 2005; Arce et al, 2006; Candelaria et al, 2007; Prince et al, 2009; Rocca et al, 2009). Our study suggests that at least in the preclinical setting, TSA-related compounds may offer the better blend of effectiveness and specificity for lung and breast cancer and melanomas. This may potentially also hold in the setting of combination therapy. A recent study by Frenkel, Gazdar and colleagues concluded that depsipeptide co-administered with EGFR inhibitors gave a substantial advantage over EGFR inhibitors alone in xenograft models of lung cancer (Zhang et al, 2009). Parallel studies comparing several HDAC inhibitors in combination with standard chemotherapies or targeted therapies will be needed to identify the most effective and safe combinations. Since vorinostat already has approval status, this would be a rational first choice of HDAC inhibitor, as several cancer centres with currently open trials have already realised.

\section{ACKNOWLEDGEMENTS}

We are grateful to Drs John Minna and Adi Gazdar for sharing a large collection of non-small cell lung cancer cells and bronchial epithelial cells, and to Shelley Sheridan for immortalising epithelial cells. We thank MK Hyland for technical assistance with MDR western blots. We are indebted to Dr David Schrump for the generous gift of depsipeptide. Human breast cancer cells and immortalised mammary epithelial cells were the kind gift of Drs Cheryl Lewis and David Euhus. Melanoma cell lines were received from the NCI and uveal melanoma lines were generously provided by Jerry Niederkorn. This study was supported by the NCI (K22CA11871703 and R01CA12526901 to EDM), by Galderma (grant to EDM) and by the Doctors Cancer Foundation (Nolan Miller Lung Cancer grant to EDM).

Supplementary Information accompanies the paper on British Journal of Cancer website (http://www.nature.com/bjc)

\section{REFERENCES}

Arce C, Perez-Plasencia C, Gonzalez-Fierro A, de la Cruz-Hernandez E, Revilla-Vazquez A, Chavez-Blanco A, Trejo-Becerril C, Perez-Cardenas E, Taja-Chayeb L, Bargallo E, Villarreal P, Ramirez T, Vela T, Candelaria M, Camargo MF, Robles E, Duenas-Gonzalez A (2006) A proof-of-principle study of epigenetic therapy added to neoadjuvant doxorubicin cyclophosphamide for locally advanced breast cancer. PLoS One 1: e98

Bieliauskas AV, Pflum MK (2008) Isoform-selective histone deacetylase inhibitors. Chem Soc Rev 37: $1402-1413$

Bolden JE, Peart MJ, Johnstone RW (2006) Anticancer activities of histone deacetylase inhibitors. Nat Rev Drug Discov 5: 769-784

Candelaria M, Gallardo-Rincon D, Arce C, Cetina L, Aguilar-Ponce JL, Arrieta O, Gonzalez-Fierro A, Chavez-Blanco A, de la Cruz-Hernandez E Camargo MF, Trejo-Becerril C, Perez-Cardenas E, Perez-Plasencia C, Taja-Chayeb L, Wegman-Ostrosky T, Revilla-Vazquez A, DuenasGonzalez A (2007) A phase II study of epigenetic therapy with hydralazine and magnesium valproate to overcome chemotherapy resistance in refractory solid tumors. Ann Oncol 18: 1529-1538

Cantor JP, Iliopoulos D, Rao AS, Druck T, Semba S, Han SY, McCorkell KA, Lakshman TV, Collins JE, Wachsberger P, Friedberg JS, Huebner K (2007) Epigenetic modulation of endogenous tumor suppressor expression in lung cancer xenografts suppresses tumorigenicity. Int J Cancer 120: 24-31

Chen CS, Weng SC, Tseng PH, Lin HP, Chen CS (2005) Histone acetylationindependent effect of histone deacetylase inhibitors on Akt through the reshuffling of protein phosphatase 1 complexes. J Biol Chem 280: $38879-38887$

Clapier CR, Cairns BR (2009) The biology of chromatin remodeling complexes. Annu Rev Biochem 78: 273-304

Crabb SJ, Howell M, Rogers H, Ishfaq M, Yurek-George A, Carey K, Pickering BM, East P, Mitter R, Maeda S, Johnson PW, Townsend P, Shin-ya K, Yoshida M, Ganesan A, Packham G (2008) Characterisation of the in vitro activity of the depsipeptide histone deacetylase inhibitor spiruchostatin A. Biochem Pharmacol 76: $463-475$

Di Gennaro E, Bruzzese F, Caraglia M, Abruzzese A, Budillon A (2004) Acetylation of proteins as novel target for antitumor therapy: review article. Amino Acids 26: 435-441

Duvic M, Vu J (2007) Vorinostat: a new oral histone deacetylase inhibitor approved for cutaneous T-cell lymphoma. Expert Opin Investig Drugs 16: $1111-1120$

Ekwall K (2005) Genome-wide analysis of HDAC function. Trends Genet 21: $608-615$

Facchetti F, Previdi S, Ballarini M, Minucci S, Perego P, La Porta CA (2004) Modulation of pro- and anti-apoptotic factors in human melanoma cells exposed to histone deacetylase inhibitors. Apoptosis 9: 573-582

Fischle W, Kiermer V, Dequiedt F, Verdin E (2001) The emerging role of class II histone deacetylases. Biochem Cell Biol 79: 337-348

Forbes SA, Tang G, Bindal N, Bamford S, Dawson E, Cole C, Kok CY, Jia M, Ewing R, Menzies A, Teague JW, Stratton MR, Futreal PA (2010) COSMIC (the Catalogue of Somatic Mutations in Cancer): a resource to investigate acquired mutations in human cancer. Nucleic Acids Res 38: D652 - D657

Furumai R, Matsuyama A, Kobashi N, Lee KH, Nishiyama M, Nakajima H, Tanaka A, Komatsu Y, Nishino N, Yoshida M, Horinouchi S (2002) FK228 (depsipeptide) as a natural prodrug that inhibits class I histone deacetylases. Cancer Res 62: 4916-4921

Itoh Y, Suzuki T, Miyata N (2008) Isoform-selective histone deacetylase inhibitors. Curr Pharm Des 14: 529-544

Jones P, Steinkuhler C (2008) From natural products to small molecule ketone histone deacetylase inhibitors: development of new class specific agents. Curr Pharm Des 14: 545-561

Kelly WK, Marks PA (2005) Drug insight: Histone deacetylase inhibitors development of the new targeted anticancer agent suberoylanilide hydroxamic acid. Nat Clin Pract Oncol 2: 150-157

Klisovic DD, Klisovic MI, Effron D, Liu S, Marcucci G, Katz SE (2005) Depsipeptide inhibits migration of primary and metastatic uvea melanoma cell lines in vitro: a potential strategy for uveal melanoma. Melanoma Res 15: $147-153$

Lee KW, Kim JH, Park JH, Kim HP, Song SH, Kim SG, Kim TY, Jong HS, Jung KH, Im SA, Kim TY, Kim NK, Bang YJ (2006) Antitumor activity of SK-7041, a novel histone deacetylase inhibitor, in human lung and breast cancer cells. Anticancer Res 26: $3429-3438$ 
Lin HY, Chen CS, Lin SP, Weng JR, Chen CS (2006) Targeting histone deacetylase in cancer therapy. Med Res Rev 26: 397-413

Lynch TJ, Bell DW, Sordella R, Gurubhagavatula S, Okimoto RA, Brannigan BW, Harris PL, Haserlat SM, Supko JG, Haluska FG, Louis DN, Christiani DC, Settleman J, Haber DA (2004) Activating mutations in the epidermal growth factor receptor underlying responsiveness of non-small-cell lung cancer to gefitinib. $N$ Engl J Med 350: 2129-2139

Marshall JC, Lee JH, Steeg PS (2009) Clinical-translational strategies for the elevation of Nm23-H1 metastasis suppressor gene expression. Mol Cell Biochem 329: $115-120$

McLaughlin F, La Thangue NB (2004) Histone deacetylase inhibitors open new doors in cancer therapy. Biochem Pharmacol 68: 1139-1144

Miyanaga A, Gemma A, Noro R, Kataoka K, Matsuda K, Nara M, Okano T, Seike M, Yoshimura A, Kawakami A, Uesaka H, Nakae H, Kudoh S (2008) Antitumor activity of histone deacetylase inhibitors in non-small cell lung cancer cells: development of a molecular predictive model. Mol Cancer Ther 7: $1923-1930$

Mukhopadhyay NK, Weisberg E, Gilchrist D, Bueno R, Sugarbaker DJ, Jaklitsch MT (2006) Effectiveness of trichostatin A as a potential candidate for anticancer therapy in non-small-cell lung cancer. Ann Thorac Surg 81: 1034-1042

Peart MJ, Tainton KM, Ruefli AA, Dear AE, Sedelies KA, O'Reilly LA, Waterhouse NJ, Trapani JA, Johnstone RW (2003) Novel mechanisms of apoptosis induced by histone deacetylase inhibitors. Cancer Res 63: $4460-4471$

Phelps RM, Johnson BE, Ihde DC, Gazdar AF, Carbone DP, McClintock PR, Linnoila RI, Matthews MJ, Bunn Jr PA, Carney D, Minna JD, Mulshine JL (1996) NCI-navy medical oncology branch cell line data base. J Cell Biochem Suppl 24: $32-91$

Prince HM, Bishton MJ, Harrison SJ (2009) Clinical studies of histone deacetylase inhibitors. Clin Cancer Res 15: 3958-3969

Qiu Y, Zhao Y, Becker M, John S, Parekh BS, Huang S, Hendarwanto A, Martinez ED, Chen Y, Lu H, Adkins NL, Stavreva DA, Wiench M, Georgel PT, Schiltz RL, Hager GL (2006) HDAC1 acetylation is linked to progressive modulation of steroid receptor-induced gene transcription. Mol Cell 22: 669-679

Ramirez RD, Sheridan S, Girard L, Sato M, Kim Y, Pollack J, Peyton M, Zou Y, Kurie JM, Dimaio JM, Milchgrub S, Smith AL, Souza RF, Gilbey L, Zhang X, Gandia K, Vaughan MB, Wright WE, Gazdar AF, Shay JW, Minna JD (2004) Immortalization of human bronchial epithelial cells in the absence of viral oncoproteins. Cancer Res 64: 9027-9034

Ren DH, Mayhew E, Hay C, Li H, Alizadeh H, Niederkorn JY (2004) Uveal melanoma expression of tumor necrosis factor-related apoptosisinducing ligand (TRAIL) receptors and susceptibility to TRAIL-induced apoptosis. Invest Ophthalmol Vis Sci 45: 1162-1168

Riester D, Hildmann C, Schwienhorst A (2007) Histone deacetylase inhibitors - turning epigenic mechanisms of gene regulation into tools of therapeutic intervention in malignant and other diseases. Appl Microbiol Biotechnol 75: 499-514

Rocca A, Minucci S, Tosti G, Croci D, Contegno F, Ballarini M, Nole F, Munzone E, Salmaggi A, Goldhirsch A, Pelicci PG, Testori A (2009) A phase I-II study of the histone deacetylase inhibitor valproic acid plus chemoimmunotherapy in patients with advanced melanoma. Br J Cancer 100: $28-36$

Ryan QC, Headlee D, Acharya M, Sparreboom A, Trepel JB, Ye J, Figg WD, Hwang K, Chung EJ, Murgo A, Melillo G, Elsayed Y, Monga M, Kalnitskiy M, Zwiebel J, Sausville EA (2005) Phase I and pharmacokinetic study of MS-275, a histone deacetylase inhibitor, in patients with advanced and refractory solid tumors or lymphoma. J Clin Oncol 23: 3912-3922

Sadoul K, Boyault C, Pabion M, Khochbin S (2008) Regulation of protein turnover by acetyltransferases and deacetylases. Biochimie 90: 306-312
Sandor V, Bakke S, Robey RW, Kang MH, Blagosklonny MV, Bender J, Brooks R, Piekarz RL, Tucker E, Figg WD, Chan KK, Goldspiel B, Fojo AT, Balcerzak SP, Bates SE (2002) Phase I trial of the histone deacetylase inhibitor, depsipeptide (FR901228, NSC 630176), in patients with refractory neoplasms. Clin Cancer Res 8: 718-728

Sato M, Vaughan MB, Girard L, Peyton M, Lee W, Shames DS, Ramirez RD, Sunaga N, Gazdar AF, Shay JW, Minna JD (2006) Multiple oncogenic changes (K-RAS(V12), p53 knockdown, mutant EGFRs, p16 bypass, telomerase) are not sufficient to confer a full malignant phenotype on human bronchial epithelial cells. Cancer Res 66: 2116-2128

Schrump DS, Nguyen DM, Kunst TE, Hancox A, Figg WD, Steinberg SM, Pishchik V, Becerra Y (2002) Phase I study of sequential deoxyazacytidine/depsipeptide infusion in patients with malignancies involving lungs or pleura. Clin Lung Cancer 4: 186-192

Schultz BE, Misialek S, Wu J, Tang J, Conn MT, Tahilramani R, Wong L (2004) Kinetics and comparative reactivity of human class I and class IIb histone deacetylases. Biochemistry 43: 11083 - 11091

Shames DS, Girard L, Gao B, Sato M, Lewis CM, Shivapurkar N, Jiang A, Perou CM, Kim YH, Pollack JR, Fong KM, Lam CL, Wong M, Shyr Y, Nanda R, Olopade OI, Gerald W, Euhus DM, Shay JW, Gazdar AF, Minna JD (2006) A genome-wide screen for promoter methylation in lung cancer identifies novel methylation markers for multiple malignancies. PLoS Med 3: e486

Stimson L, La Thangue NB (2009) Biomarkers for predicting clinical responses to HDAC inhibitors. Cancer Lett 280: 177-183

Takai N, Narahara H (2010) Histone deacetylase inhibitor therapy in epithelial ovarian cancer. J Oncol 2010: 458431

Vigushin DM, Ali S, Pace PE, Mirsaidi N, Ito K, Adcock I, Coombes RC (2001) Trichostatin A is a histone deacetylase inhibitor with potent antitumor activity against breast cancer in vivo. Clin Cancer Res 7: 971-976

Villar-Garea A, Esteller M (2004) Histone deacetylase inhibitors: understanding a new wave of anticancer agents. Int J Cancer 112: 171-178

Witt O, Deubzer HE, Milde T, Oehme I (2009) HDAC family: what are the cancer relevant targets? Cancer Lett 277: 8-21

Wu LP, Wang X, Li L, Zhao Y, Lu S, Yu Y, Zhou W, Liu X, Yang J, Zheng Z, Zhang H, Feng J, Yang Y, Wang H, Zhu WG (2008) Histone deacetylase inhibitor depsipeptide activates silenced genes through decreasing both CpG and H3K9 methylation on the promoter. Mol Cell Biol 28: 3219-3235

Xiao JJ, Byrd J, Marcucci G, Grever M, Chan KK (2003) Identification of thiols and glutathione conjugates of depsipeptide FK228 (FR901228), a novel histone protein deacetylase inhibitor, in the blood. Rapid Commun Mass Spectrom 17: 757-766

Zhang W, Peyton M, Xie Y, Soh J, Minna JD, Gazdar AF, Frenkel EP (2009) Histone deacetylase inhibitor romidepsin enhances anti-tumor effect of erlotinib in non-small cell lung cancer (NSCLC) cell lines.J Thorac Oncol 4: $161-166$

Zhang XH, Rao M, Loprieato JA, Hong JA, Zhao M, Chen GZ, Humphries AE, Nguyen DM, Trepel JB, Yu X, Schrump DS (2008) Aurora A, Aurora $B$ and survivin are novel targets of transcriptional regulation by histone deacetylase inhibitors in non-small cell lung cancer. Cancer Biol Ther 7: $1388-1397$

Zhao Y, Lu S, Wu L, Chai G, Wang H, Chen Y, Sun J, Yu Y, Zhou W, Zheng Q, Wu M, Otterson GA, Zhu WG (2006) Acetylation of p53 at lysine $373 / 382$ by the histone deacetylase inhibitor depsipeptide induces expression of p21(Waf1/Cip1). Mol Cell Biol 26: 2782-2790

Zhong S, Fields CR, Su N, Pan YX, Robertson KD (2007) Pharmacologic inhibition of epigenetic modifications, coupled with gene expression profiling, reveals novel targets of aberrant DNA methylation and histone deacetylation in lung cancer. Oncogene 26: 2621-2634

This work is published under the standard license to publish agreement. After 12 months the work will become freely available and the license terms will switch to a Creative Commons Attribution-NonCommercial-Share Alike 3.0 Unported License. 